\title{
Ethnic and Regional Differences in the Management of Angina: The Way Forward
}

\author{
Jack C Barton (1) and Juan Carlos Kaski (D² \\ 1. Critical Care and Perioperative Medicine Research Group, Royal London Hospital, London, UK; \\ 2. Molecular and Clinical Sciences Research Institute, St George's University of London, London, UK
}

\begin{abstract}
For decades, there has been great interest in ethnic differences in the management of angina and stable cardiovascular disease. Clinical decisionmaking is known to be both consciously and unconsciously influenced by a patient's demographics, and this is due to in part to differences in clinical guidance and opinion. However, the evidence supporting such decision-making is sparse. Nonetheless, there is overwhelming evidence that international, national, regional, institutional, departmental and individual bias disproportionately affect subgroups of the population, resulting in adverse patient outcomes. While without doubt there will be rapid advancements in individualised therapies over the coming years and decades, the most beneficial immediate action clinicians can take is to reduce disparities in both the evidence base and care provision. Doing so will require great collaborative effort.
\end{abstract}

\section{Keywords}

Angina, coronary artery disease, microvascular angina, ethnicity

Disclosure: JCK is Editor-in-Chief of European Cardiology Review. JCB has no conflicts of interest to declare.

Received: 20 December 2021 Accepted: 21 December 2021 Citation: European Cardiology Review 2022;17:e07. DOI: https;//doi.org/10.15420/ecr.2021.60

Correspondence: Jack Barton, Critical Care and Perioperative Medicine Research Group, Royal London Hospital, Whitechapel Rd, London E1 1FR, UK.

E: jack.barton@nhs.net

Open Access: This work is open access under the CC-BY-NC 4.0 License which allows users to copy, redistribute and make derivative works for non-commercial purposes, provided the original work is cited correctly.

The last 2 years have forced repetitive and uncomfortable processes of introspection as we are faced with undeniable evidence of health inequalities worldwide. The stark reality that the colour of your skin, the neighbourhood in which you were raised and the money in your pocket would determine your risk of mortality during the most dangerous period of our generation is impossible to ignore or act upon. In doing so, we are forced to consider not only the academic and policy implications of these factors on communicable diseases but also the impact they have on daily clinical practice when managing patients with non-communicable diseases.

Clinical guidance accounts for ethnic difference in both prevalence of disease and trial data supporting variance in treatment efficacy, perhaps most recognisably in terms of guidance surrounding the management of primary hypertension. ${ }^{2}$ Supporting data for said guidance has been derived primarily from large observational trials originating from the US in the late 20th and early 21st centuries. ${ }^{3,4}$

However, these trials should be recognised for what they are - broad brushstrokes susceptible to known and unknown confounders. They are more likely to reflect social and cultural variables than the genetic mechanisms that are commonly used to justify observed differences in outcomes. ${ }^{5}$ This is ironic, considering that the true meaning of ethnicity reflects a complex, multidimensional social construct rather than a proxy for physical and geographical characteristics.

As the use of polygenic risk scores, genome-wide association studies and other more advanced methods of subcategorising study participants become more readily available, it is highly likely that while some of our existing assumptions may well gain credence, a large proportion will instead be attributed to suboptimal study design and socioeconomic or cultural factors. ${ }^{6}$

This, of course, provides little in the way of reassurance for clinicians making daily management decisions for their patients. However, it should, at a minimum, encourage us to be wary of allocating our patients to clearly defined but largely arbitrary groups based upon their age and ethnicity.

Moreover, in consciously considering variables that disproportionately affect subgroups of our patient population, we may be able to identify system-wide bias or even our own biases that may be contributing to suboptimal outcomes?

What for our cardiovascular pharmacological strategies? While individualising treatment and pharmacotherapy may be an interesting academic exercise and may yield recognisable benefits for our patients, it is important to acknowledge the relatively small impact that many of our most strongly evidenced therapies have. ${ }^{8}$ In doing so, we must recognise our own susceptibility to unconscious bias in the allocation of even wellvalidated interventions. ${ }^{9}$

Such is the strength of system-wide, institutional and physician bias or barriers to access of medical services among certain ethnic groups that some studies suggest that appropriate adjustment for said factors all but removes the difference between patient outcomes observed..$^{10}$ Hence, 
the hesitancy within this article to suggest that any strong data to support adapting treatment based upon ethnicity exist at all.

Additionally, one may argue that cultural factors that influence adherence to and availability of prescribed medications may have a greater influence on the efficacy of treatments than the subtle differences between pharmacodynamics in similar drug classes.

For example, adherence with aspirin therapy in those with and without stable coronary artery disease varies dramatically between ethnic groups. ${ }^{11}$ It is likely that any interventions targeting problems such as this will have a far greater clinical impact than further investigation into potential genetic differences between ethnic subgroups. ${ }^{12}$

Of course, this is not to dissuade those looking to expand a body of literature that has guided current best practice, but largely ignored swathes of the population. This is particularly so given that the future of cardiovascular prescribing may well lie in gene-guided therapy, the investigation of which may itself be guided by identification of differences between phenotypical groups. ${ }^{13,14}$ We are sure even the most disinterested reader would agree that justifying high-risk prescribing decisions based upon CYP2C19 presence would at least go some way to reducing our own anxieties, if not reducing risk to our patients.

Unfortunately, to the authors' knowledge, scientific progress in the management of stable coronary artery disease and angina has been poor and has lagged over the past decade regarding ethnic differences observed in response to both rate-controlling drugs and more novel therapies. As researchers, we shoulder a large proportion of the blame for this, as reporting of ethnicity within recent literature remains pitiful and, in studies that do report ethnicity, the majority still recruit participants from a majority white cohort of patients. ${ }^{15}$

Research into less prevalent, diagnosable and treatable conditions such as microvascular angina may approach these challenges from a different and more bountiful vantage point. Primary studies into such conditions may draw from the lessons of large early trials into their occlusive, highly prevalent counterparts, and actively recruit subgroups of the population who were disproportionately represented in the 20th century.

Additionally, one may argue that research into ethnic and thus potential genetic differences in the pathophysiology and thus the amenability to pharmacotherapy of microvascular angina may yield more significant results than those observed in stable coronary artery disease. We arrive at this rather more positive conclusion from considering that the underlying pathophysiology of the condition includes a range of heterogenous and, to some extent, distinct mechanisms observed disproportionately in certain subsets of the population. ${ }^{16}$

However, the difficulties in diagnosis and a lack of international consensus on the management of microvascular angina means that understanding of the implications of variables such as ethnicity is limited. The relatively low prevalence (or at least recorded prevalence) of such conditions means that recruiting trial participants from black and ethnic minority groups is likely to remain difficult. ${ }^{17}$ However, active efforts in the form of large, multicentre international collaborative work to overcome such difficulties are ongoing. ${ }^{18}$

The same bears true for coronary spasm, whereby ethnic difference is likely to have an even greater influence on pharmacological research and clinical decision-making. ${ }^{19}$ Recent cohort studies in this area suggest that there are differences between the clinical profiles of patients from different ethnic backgrounds. However, much like within microvascular angina, evidence to justify variation in prescribing between patient groups is sparse.

That is not to say that there is not a clear disparity in the rates of prescription of certain therapies between ethnic groups, which may itself contribute to the observed difference in mortality..$^{19}$ Again, we appear biased not only as researchers, but also as clinicians.

The key academic issue, as with microvascular angina, is primarily related to a lack of multicentre, large-scale trials investigating different phenotypes. ${ }^{18}$ This is unsurprising given the great difficulty in diagnosing and managing these conditions, and thus the even greater difficulty in organising and recruiting to large-scale trials.

Ultimately, there is clear evidence that organising efforts into reducing disparity in recognition, diagnosis, management decisions and adherence with pharmacotherapies between ethnic groups is likely to yield the most significant short- to medium-term benefits. Yet the observed differences in outcomes between ethnic groups is likely to at least in part result from a true and meaningful difference in genetic phenotypes that will in the long term be used to guide our pharmacotherapies.

For now and in the the foreseeable future, it remains certain that most of this difference is due to cultural and social factors, as well as our individual and systemic biases. To overcome both the procedural and academic barriers to optimal anginal care in the future, large-scale, cohesive, collaborative effort is necessary.

We are now in a better position than ever to facilitate this. We have both the technology and the will to rapidly amass huge amounts of data to guide our efforts. ${ }^{20}$ Nonetheless, we must ensure that we do not perpetuate the same errors in research as occurred throughout the late 1900 s and, unfortunately, to present day. We must be wary of drawing conclusions based on observational data that is exposed to known and unknown confounders, particularly when drawing arbitrary lines in patient populations based upon ethnicity. We must also ensure we actively recruit patients of black and ethnic minority backgrounds, publishing data on them while recognising the limitations of drawing conclusions based upon these data.

Over the coming decades, there will be great advances in clinicians' ability to guide cardiovascular pharmacotherapy based upon genotyping, which may or may not go some way to reducing the differences in outcomes observed between ethnic groups. However, such advancements will be nothing more than a drop in the ocean in comparison to what could be achieved by reducing inequality between said groups and targeting public health interventions towards those who need it most. $\square$ 
1. Bambra C, Riordan R, Ford J, et al. The COVID-19 pandemic and health inequalities. J Epidemiol Community Health 2020;74:964-8. https://doi.org/10.1136/jech-2020-214401; PMID: 32535550

2. Deere BP, Ferdinand KC. Hypertension and race/ethnicity. Am J Med Sci 2020;35:342-350. https://doi.org/10.1097/ MAJ.0000000000000308; PMID: 24983758

3. Wright JT, Dunn JK, Cutler JA, et al. Outcomes in hypertensive black and nonblack patients treated with chlorthalidone, amlodipine, and lisinopril. JAMA 2005:293:1595-608. https://doi.org/10.1001 jama.293.13.1595; PMID: 15811979.

4. Ogedegbe G, Shah NR, Phillips C, et al. Comparative effectiveness of angiotensin-converting enzyme inhibitorbased treatment on cardiovascular outcomes in hypertensive blacks versus whites. J Am Coll Cardiol 2015;66:1224-33. https://doi.org/10.1016/j.jacc.2015.07.021; PMID: 26361152.

5. Ferdinand $\mathrm{KC}$, Igari $\mathrm{M}$. The role of racial/ethnic factors in global clinical trials. Expert Rev Clin Pharmacol 2018;11:82932. https://doi.org/10.1080/17512433.2018.1510311; PMID: 30099916.

6. Mu G, Xiang Q, Zhou S, et al. Association between genetic polymorphisms and angiotensin-converting enzyme inhibitor-induced cough: a systematic review and metaanalysis. Pharmacogenomics 2019;20:189-212. https://doi. org/10.2217/pgs-2018-0157; PMID: 30672376

7. Graham G. Disparities in cardiovascular disease risk in the United States. Curr Cardiol Rev 2015;11:238-45. https://doi. org/10.2174/1573403X11666141122220003: PMID: 25418513

8. Berger JS, Lala A, Krantz MJ, et al. Aspirin for the prevention of cardiovascular events in patients without clinical cardiovascular disease: a meta-analysis of randomized trials. Am Heart J 2011;162:115-24.e2. https://doi.org/10.1016/j. ahj.2011.04.006; PMID: 21742097.

9. Shaw LJ, Shaw RE, Merz CNB, et al. Impact of ethnicity and gender differences on angiographic coronary artery disease prevalence and in-hospital mortality in the American College of Cardiology - National Cardiovascular Data Registry. Circulation 2008:117:1787-801. https://doi.org/10.116 CIRCULATIONAHA.107.726562; PMID: 18378615.

10. Iribarren C, Tolstykh I, Somkin CP, et al. Sex and racial/ethnic disparities in outcomes after acute myocardial infarction: a cohort study among members of a large integrated health care delivery system in northern California. Arch Intern Med 2005;165:2105-13. https://doi.org/10.1001/ archinte.165.18.2105; PMID: 16217000

11. Brown DW, Shepard D, Giles WH, et al. Racial differences in the use of aspirin: an important tool for preventing heart disease and stroke. Ethn Dis 2005;15:620-6; PMID: 16259485.

12. Lev El, Bliden KP, Jeong YH, et al. Influence of race and sex on thrombogenicity in a large cohort of coronary artery disease patients. J Am Heart Assoc 2014;3:e001167. https:// doi.org/10.1161/JAHA.114.001167; PMID: 25332180.

13. Zhang H, Xiang Q, Liu Z, et al. Genotype-guided antiplatelet treatment versus conventional therapy: a systematic review. and meta-analysis. Br J Clin Pharmacol 2021;87:2199-215. https://doi.org/10.1111/bcp.14637; PMID: 33140858

14. Jafrin S, Naznin NE, Reza MS, et al. Risk of stroke in CYP2C19 LoF polymorphism carrier coronary artery disease patients undergoing clopidogrel therapy: an ethnicity based updated meta-analysis. Eur J Intern Med 2021;90:49 65. https://doi.org/10.1016/j.ejim.2021.05.022
PMID: 34092486

15. Tahhan AS, Vaduganathan M. Greene SJ, et al. Enrollment of older patients, women, and racial and ethnic minorities in contemporary heart failure clinical trials: a systematic review. JAMA Cardio/ 2018;3:1011-9. https://doi.org/10.1001/ jamacardio.2018.2559; PMID: 30140928.

16. Kaski JC, Crea F, Gersh BJ, Camici PG. Reappraisal of ischemic heart disease. Circulation 2018;138:1463-80. https://doi.org/10.1161/CIRCULATIONAHA.118.031373; PMID: 30354347.

17. Suda A, Takahashi J, Beltrame JF, et al. International prospective cohort study of microvascular angina rationale and design. Int J Cardiol Heart Vasc 2020;31:100630 https://doi.org/10.1016/j.ijcha.2020.100630; PMID: 32984497.

18. Shimokawa H, Suda A, Takahashi J, et al Clinical characteristics and prognosis of patients with microvascular angina: an international and prospective cohort study by the Coronary Vasomotor Disorders International Study (COVADIS) Group. Eur Heart J 2021;42:4592-600. https://doi. org/10.1093/eurheartj/ehab282; PMID: 34038937.

19. Sato K, Takahashi J, Odaka Y, et al. Clinical characteristics and long-term prognosis of contemporary patients with vasospastic angina: ethnic differences detected in an international comparative study. Int J Cardiol 2019;291:13-8. https://doi.org/10.1016/j.ijcard.2019.02.038; PMID: 30819587.

20. George J, Mathur R, Shah AD, et al. Ethnicity and the first diagnosis of a wide range of cardiovascular diseases: associations in a linked electronic health record cohort of 1 million patients. PLoS One 2017:12:e0178945 https://doi. org/10.1371/journal.pone.0178945; PMID: 28598987. 